International Journal of Linguistics, Literature and Translation

ISSN: 2617-0299 (Online); ISSN: 2708-0099 (Print)

DOI: $10.32996 / \mathrm{ijllt}$

Journal Homepage: www.al-kindipublisher.com/index.php/ijllt

\title{
Communicative Language Teaching (CLT) Strategies in Daily Lesson Plans of Oral Communication Teachers and their Alignment to Standards in Curriculum Guide
}

\author{
Darwin D. Bargo' $\mathbf{8}(\mathrm{D}) \square$ and Mildred B. Go ${ }^{2} \mathrm{~B}$ \\ ${ }^{1}$ Graduate Student, Centro Escolar University (CEU), Manila, Philippines / Education Program Supervisor, Curriculum \\ Implementation Division, DepEd - Schools Division Office of Antipolo City, Rizal, Philippines \\ ${ }^{2}$ Graduate School Professorial Lecturer, Centro Escolar University (CEU), Manila, Philippines
}

$\triangle$ Corresponding Author: Darwin D. Bargo, E-mail: bargo1615223@ceu.edu.ph / darwin.bargo@deped.gov.ph

\section{ARTICLE INFORMATION}

Received: May 09, 2021

Accepted: June 10, 2021

Volume: 4

Issue: 6

DOI: $10.32996 /$ ijllt.2021.4.6.11

\section{KEYWORDS}

Communicative Language

Teaching (CLT) strategies, lesson

plans, alignment to standards,

curriculum guide

\section{ABSTRACT}

Communicative Language Teaching (CLT) is an approach that has been the subject of many practitioners and researchers in the field of language teaching and applied linguistics in many countries like the Philippines because of the recent changes and educational reforms, including lessons and curriculum innovations. Anchored to the CLT theory, this study used quantitative-qualitative content analysis of the daily lesson plans of the 7 purposively sampled Senior High School (SHS) language teachers teaching Oral Communication in Context (OCC). This aimed to identify the activities by cluster, assess which activities are CLT strategies, and determine their alignment to standards in the curriculum guide. Results revealed that the strategies used as classified through content analysis, and according to type and frequency included task-completion activity, opinion-sharing activity, mechanical practice activity, information-transfer activity, reasoning-gap activity, information-gap activity, communicative activity, information-gathering activity, fluency activity, accuracy activity, meaningful practice activity, and others. A number of strategies matched the CLT principles and features but vary on their respective percentages in each of the four phases, i.e., Activity-Analysis-Abstraction-Application (4As) of the lesson. These CLT strategies were found to be aligned to the Department of Education's curriculum guide in terms of content standards, performance standards and assessment types. Implications of the findings to language teaching in the Philippines were drawn.

\section{Introduction}

Communicative Language Teaching (CLT) is an approach that can be traced back to the early 20th century, introduced in 1960s, further developed in 1970s, and continued to flourish in 1980s. This has been the subject of many practitioners and researchers in the field of language teaching in many countries. The CLT has become a hybrid approach of the teachers in their teaching of grammar and communication arts and skills-related exercises because of the diverse learners with multifaceted needs. As cited, Howat (1984) in Aicart (2015) has two CLT definitions: the strong and the weak version. The former says grammar or structure or language form is acquired through communication and entails using the language to learn it. On the other hand, the latter which also means learning to use the language and has become the standards nowadays stresses the importance of using the language for communicative purposes within a wider program in language teaching. This signifies that activities involving real communication promote learning, and these activities are selected according to how well they engage the learner in meaningful language use.

In some countries, there were researches undertaken about CLT in various levels, such as basic education and higher education. These were also studies exploring varied variables revolving the communicative classroom teaching that obviously pertains to CLT, teachers and students. For instance, in Ecuador, Toro et al. (2019) on the use of CLT in improving students' oral skills; in

\section{K C AL-KINDI CENTER $\mathbf{R}$ D FOR RESEARCH AND DEVELOPMENT} Your gateway to world-class research

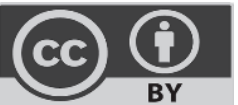

Published by Al-Kindi Center for Research and Development, London, United Kingdom. Copyright (c) the author(s). This open access article is distributed under a Creative Commons Attribution (CC-BY) 4.0 license 
Bangladish, Rahman et al. (2018a) on factors affecting teachers' implementation of the CLT curriculum in secondary schools; Rahman et al. (2018b) on beliefs and practices relating to CLT; and Ahmed (2016) on implementation of CLT in the language teaching and learning environment; in England, Guzman-Alcon (2019) on the principles of CLT in primary-education classrooms; and in Albania, Kapurani (2016) on the implementation of CLT in elementary schools, to mention some.

In the Philippines, there had been studies done on CLT already, and it seems to be an interesting topic in applied linguistics because of the changes and reforms in the educational set-up where the curriculum is enhanced, if not totally changed. The works of Manzano (2015); and Maestre \& Gandidis (2016), dealt with beliefs, practices and challenges in adopting CLT in the Philippine set-up, while the study of Baena (2013) focused on the implementation of communicative language teaching (CLT) approach towards a faculty development program. These studies were within the Philippine context, which explored the CLT to promote communicative competence through varied authentic teaching-learning situations in the classrooms. It can also be inferred that it takes the stand on the significance of CLT when adopted in English or language classrooms.

Although these mentioned studies were all focused on CLT, and similar in nature, they could not touch on its application to the senior high school programs of the $\mathrm{K}$ to 12 Curriculum. They also failed to show the type of activities in the classrooms and the extent of alignment of the activities and CLT strategies to the curriculum standards set by the DepEd in the curriculum guide for the subject oral communication in context taught by the senior high school language teachers.

The present study attempted to find out the types and frequencies of the activities given by the teachers to their students as reflected in their daily lesson plans. This also investigated which of the identified activities in the four phases of the lessons are considered CLT strategies considering the CLT principles and features. After such investigation, this study further determined the extents of alignment of these CLT strategies to the curriculum standards set by the DepEd for senior high school subjects.

This study will be helpful to the language teachers and the senior high school students, for they are the ultimate reason this study was undertaken. The findings of the study will guide the language teachers in the senior high schools and all other CLT practitioners in the Philippines and in other countries. In other words, the results of this study will benefit the senior high school teachers and students and even ELT classrooms.

This paper followed the models of communicative competence as it assessed the activities and CLT strategies in lessons' phases, and further investigated their alignment to the curriculum standards set by the DepEd on the subjects for the senior high school such as the one used in this study, the Oral Communication in Context that is offered to the SHS classrooms in the Schools Division Office of Antipolo City.

\section{Background of the Study}

Having been a teacher of all the English related subjects offered in the senior high schools for more than two years of the implementation of Grades 11 and 12 Programs in the $\mathrm{K}$ to 12 Curriculum, and even before its implementation, when these subjects were part of the General Education Curriculum in the colleges and universities, the researcher had already in mind to scrutinize the lesson plans of the teachers teaching oral communication in context, through a study like this, so as to know the reasons and other factors that contribute to the performance and masterly level of the skills and competencies of the students under the same subject. This is congruent to the works of Shalem et al. (2018), in South Africa, on teacher autonomy in times of standardized lesson plans; and Koyunkaya \& Tasdan (2019), in Turkey, on lesson plans prepared by pre-service teachers in a technology-based course.

In the context of the senior high school teachers, the Department of Education (DepEd) issued guidelines on preparing the daily lesson plan based on the belief that planning is fundamental to ensuring the delivery of teaching and learning in schools. This is stipulated in DepEd Order No. 42, s. 2016. This order also cites Article IV, Section 2 of the Code of Ethics for Professional Teachers adopted in 1997 through Board Resolution No. 435 by the Board for Professional Teachers which states that "every teacher shall uphold the highest standards of quality education, shall make the best preparations for the career of teaching, and shall be at his best at all times in the practice of his profession." This policy is meant to support teachers in instructional planning through Daily Lesson Log (DLL) or Detailed Lesson Plan (DLP) preparation. This policy also provides templates for the parts of the log or plan in all subject areas. Along with these parts are the 4As (activity-analysis-abstraction-application) as reflected in the phases of the lesson proper, although these are embedded in the procedure a (reviewing the previous lesson or presenting the new lesson) to $\mathrm{j}$ (additional activities for application or remediation). The 4As is an approach which is expected to be adopted by the teacher as the flow of their sessions in various subjects. This is observed in the basic education classrooms, where teachers find it interactive since it considers students and teachers and materials and activities used for the lessons. It is in this part where the present study will determine if the activities under these phases match with the CLT principles and features. 
As noted in the policy, it states that experts agree that a lesson plan should aim to answer the following questions: What should be taught, how should it be taught, and how should learning be assessed? The present study's goal is to assess the alignment of the activities as practised in the SHS classrooms so that the learning outcomes will be highly observable. This is also what Martinez Gómez (2019), in his study, had noted in transitioning to communicative activities in a primary-level EFL classroom in the Dominican Republic; likewise, Varghese and Karki (2018) on preferred methods of teaching and learning the English language in Bangalore, India. As the studies back it up, teachers should really have careful planning and preparation of activities that are reflected in their respective daily lesson plans.

One cannot deny the fact that in the world of job placements, communication plays an important role. JobStreet.com has mentioned that one of the skills that employers often seek in the applicants is communicative skills. Even during interviews in the different job fairs, it could be noticed that those with good proficiency in communication and could express their views in English got the job they wanted. In an infographic posted on JobStreet.com (April, 2018), fresh graduate hiring shows shifts in demand and preferences. It also indicates that employers now claim that aside from an applicant's attitude or work ethic, they also place more consideration on communication skills and analytical thinking as top considerations when hiring fresh college graduates. This inclination toward interpersonal and 21st-century skills has emerged as a priority preference in JobStreet.com Philippines, the country's largest online job portal's, survey involving 503 employers from various parts of the country in February 2018 as part of its annual Fresh Graduate Report.

Relevant to this, Opportunity Network (2018) reveals that among the top 10 employability skills, communication skills listening, speaking and writing placed first. Employers want people who can accurately interpret what others are saying and organize and express their thoughts clearly.

In order to help resolve the communicative proficiency needs of the senior high school students who would soon be graduates and would be in their respective chosen careers or fields, the researcher thought of investigating the kind of teaching and learning process being practiced in the senior high school classrooms through the prepared daily lesson plans of the teachers. This could also be the basis for assessing if the activities and strategies adopted in various English-related subjects in the SHS classrooms are aligned to the curriculum standards. This is essential in honing the students' potentials to become communicatively competent and proficient before having their jobs. It also conforms to what Gulzar and Nasir (2019) said that alignment between standards and assessments is acknowledged to be the key factor in a standard-based education system.

With all the contexts and support ideas from the cited works, the researcher finally came to think of this study, as it is timely and relevant.

\section{Literature Review}

The related literatures and studies are arranged according to the theme and the variables reflected on the statement of the problems of the present study. These served as support ideas as reflected in the discussion of results of this study.

\section{On Teaching Activities and Strategies in Lesson Plans}

Teaching activities and strategies are always reflected and must be congruently observed by the teachers in their lesson plans. These present the target events and phases where teaching-learning occurs. Along with these activities and strategies are the factors that the teachers must take into consideration that might lead to the kind and level of students' or class' performance level and mastery of the skills expected of them. So here, the questions on how to make the lesson plan significant in the instructional process and what other embedded factors should be looked into in order to produce a lively classroom, like in the oral communication in context classes of the senior high schools should be addressed. The works of Shalem et al. (2018), Musselwhite and Wesolowski (2018), Koyunkaya and Taşdan (2019), Canbazoglu Bilici et al. (2016), Magajna and Umek (2019), Yuan and Zhang's (2016), Wen-Chi et al. (2017), Cheung Ruby and Chen (2020), Higgs (2020), Pascual (2019), Astuti and Lammers (2017), Nguyen and Gu (2020), Rojas and Villafuerte (2018), and Seltzer and de los Ríos (2018) have been useful in the discussions.

\section{On CLT Strategies in Lesson's Phases (4As) Activity Phase, Analysis Phase, Abstraction Phase and Application Phase CLT Strategies}

Communicative Language Teaching (CLT) strategies may be utilized by the teachers of oral communication in the context in the senior high schools, specifically in any of the teachers' lesson plan phases and definitely achieve its target objectives for the lesson. In the present study, the activities given by the teachers in all 4 phases are counter checked whether they are coherent with the CLT principles and features like what is presented, looked into or investigated in the works cited, including Alamri (2018), Toro et al. (2019), Rahman et al. (2018), Guzman-Alcon (2019), Kapurani (2016), Baena (2013), Maestre \& Gindidis (2016), and Manzano's (2015). 
Lesson's Phases (4As)

As stated in the Deped Order No. 42, s. 2016, the policy was issued on the belief that planning is fundamental to ensuring the delivery of teaching and learning. The policy is meant to support teachers in upholding quality education standards by affirming the importance of instructional planning through Daily Lesson Log (DLL) or Detailed Lesson Plan (DLP) preparation. This contains parts that under the procedure are the ten (10) lesson phases enumerated from a-j with respective descriptions but can also be categorized into the 4As mentioned in this order. Relative to that, considering the activity phase, are the related works of Gali et al. (2019), El Karfa (2019), Natividad and Batang (2018), Bagheri et al. (2019), Cho and Kim (2018), Al-Mashaqba (2017), and Nguyen et al. (2016). In the analysis phase, it can be noted that the studies of Huang (2016), and Martinez Gómez (2019) were useful. The abstraction phase is the part where generalization of the lesson and discussions occur. This connects to Yang's (2016). However, the last part, the application phase, may include strategies that may be part of the assessment. It is in this phase also where the evaluation part of the old format lesson plan is observed. The works cited were considered relevant to the strategies employed by the present study that is in line with CLT principles and features including Tran and Duong (2018), AL-Garni and Almuhammadi (2019), Muhammad (2016), West (2016), Varghese and Karki (2018), and Elliot (2016).

\section{On Alignment and Curriculum Standards}

There are a lot of issues and concerns that the education sector in the Philippines is now facing. These, for sure, include matters on the curriculum implementation which significantly looked into the alignment of activities to that of the competencies that are expected for the students to master and that the teachers would teach along with multifarious strategies and techniques. Thus, the DepEd has released the curriculum guides for the subjects which the students should take while they are in their basic education. This curriculum guide contains standards and competencies in the respective learning areas where the students should have to take for the whole year or academic studies. With this, the literature and studies were found to be relevant and helped the researcher widen his background considering the present study's target and objectives. This includes the works of Gulzar and Nasir (2019), Combrinck et al. (2016), Gamson et al. (2019), Ibrahim and Ibrahim (2017), Swanson and Hildebrandt (2017), Mahmadun Nuby et al. (2019), Ong et al. (2019), Rahman et al. (2018), Tassone et al. (2018), Tran et al. (2016), Jia-Li et al. (2020), Mader (2017), and Ahmed (2016).

\section{On Language Teaching Implications}

As the present study drew the implications on language teaching in the Philippines based on the present findings, the ideas similar to the enumerated themes were the studies of Moodie and Nam (2016), Ittner et al. (2019), Graves and Garton (2017), Abahussain (2016), and Dasi \& Pedersen (2016).

The reviews on literature and studies dealt with communicative language teaching: its background, principles, features and classroom practices. It also included discussion on the alignment, curriculum standards and practices as the study's anchor. It even mentioned challenges in various classrooms and levels as revealed in the local and foreign studies. The previous researchers also did intervention measures by introducing activities aiming to produce communicative learners. These were all the basis and backup of the present study. Much has been mentioned about CLT in the various literature and studies cited. None so far has dealt with variables such as lesson plans, activities, alignment, curriculum standards, and the like, as indicated in the conceptual framework of the present study, specifically in the Schools Division Office of Antipolo City.

\section{Methodology}

This study used descriptive quantitative-qualitative content analysis. Among the four ways of analysis of texts (such as content analysis, narrative structure analysis, ethnography, and ethnomethodology) in Silverman (2006), the researcher found content analysis as the most appropriate as it establishes a set of categories and counts the number of instances that fall under each category. Since the present study used the teachers' lesson plans to assess and investigate whether the activities given to the students were aligned with the CLT principles and features and the curriculum guidelines set by the DepEd, this research design was found to be the most appropriate.

\subsection{Research Procedure}

The researcher presented the research proposal of this study to the experts first for comments and approval, specifically the title and statement of the problem. The researcher then focused on constructing the introduction using CARS model of writing the introduction (Swales, 1986), and the collection of the related literature and studies and annotating them. This was followed by the formulation of chapter three and the assessment form aligned with the statement of the problems.

Before conducting the study, the researcher prepared all the things needed such as collecting the curriculum guide and the budget of work in the subject included in the study as well as lesson plans of the teachers teaching such subjects. Letter requests were sent to the Schools Division Superintendent, School Heads, Senior High School Coordinators, and Teacher-participants. 
The actual conduct of the study entailed the following steps:

1. Identifying strategies in the lesson plans. The researcher was able to identify a number of strategies used by the teacherparticipants.

2. Classifying the identified strategies as to types and frequencies in accordance to Richards (2006) and Ramadan (2017).

3. Analyzing the content of the classified strategies.

4. Matching the strategies to the CLT principles (Richards \& Rodgers, 2001) and features (Das, 2014). This was done in all four phases of the lessons, such as activity, analysis, abstraction, and application (4As).

5. Scrutinizing the alignment of the variables in the study. This was the CLT strategies to the curriculum guide considering content standards, performance standards, and assessment types.

6. Inviting inter-raters to make sure that the researcher's bias on the assessment of the activities would be avoided. The first inter-rater is an MT 1 (Master Teacher) in Junior High School, and a PhD in English Language student. The second inter-rater is a SEPS 1 (Senior Education Program Specialist) - Teacher Education Counsel - DepEd Central Office, and a PhD in English Language student. The last inter-rater is an MT 2 (Master Teacher) in SHS, handling English related subjects, and a PhD in Educational Management student.

7. Consolidating results of the ratings from the inter-raters.

8. Consolidating the data accordingly and subjecting them for statistical treatment.

9. Finally, drawing the implications through analysis and interpretation of the findings by the researcher using the content analysis research design.

\subsection{Setting, Participants and Sampling Techniques of the Study}

This study was conducted in selected senior high schools in the Schools Division Office (SDO) of Antipolo City, Rizal, Philippines. The SDO is considered a medium-sized division having $<1>$ standalone SHS and $<16>$ integrated junior-senior high schools. All senior high schools offer varied strands under Academic and TVL Tracks. Each school has its banner program based on the community need and students' interests. The participants were the 7 purposively sampled SHS language teachers who teach English (Oral Communication in Context) subject offered in the senior high school curriculum.

\subsection{Research Instruments and Validation}

Teachers' lesson plans based on DepEd Order No. 42, s. 2016 otherwise known as Policy Guidelines on Daily Lesson Preparation for the $\mathrm{K}$ to 12 Basic Education Program, were the main instruments of the study. The lesson plans that are crafted by the teachers aligned to this order contain the following parts that are also reflected in the given templates of all learning areas: Objectives, content standards, content, learning resources, procedures which include 10 parts. Although teachers are not required to go through all 10 parts in every lesson, flexibility is allowed in the delivery. Remarks and reflection are also parts of the lesson plan. The lesson phases such as 4As (Activity, Analysis, Abstraction, and Application) on page 10 of 16 are also mentioned in this guideline. Daily Lesson Log (DLL) and Detailed Lesson Plan (DLP) are the two names used to refer to the lesson plans prepared by the teachers. The DLP format includes the following parts: Objectives, Content, Learning Resources, Procedures, Remarks and Reflection. These parts have respective details to be considered by the teachers. Since the subject under this study is Oral Communication in Context and falls under the learning area of English, the Annex 2B.3 to DepEd Order No. 42, s. 2016 are used by the teachers, although this would have modifications depending on the templates re-created and approved by their department head or school heads and the preparation and submission rules set in the school like daily or weekly.

The review of the literature and studies available in various sources was exhausted by the researcher to expound the study's content and focus. This also widened the background of the researcher about issues and concerns on communicative language teaching in various contexts, noting that this study looked into the principles and features of CLT in the lessons and activities of the language teachers. The Seven Kinds of CLT Activities to Build up Students' Communicative Competence (Ramadan, 2017); CLT Principles (Richards \& Rodgers, 2001); and CLT Features (Das, 2014) were adopted in this study.

An assessment form was used in finding out and enlisting all authentic activities and practices in English (Oral Communication in Context) classes in the senior high school classrooms. The researcher utilized this with the help of the invited inter-rater to avoid biases.

The researcher constructed his own assessment form which was subjected to content and phase validation. The phases of validation were carried out through the help and assistance of the experts and practitioners in the field, the master teachers of English, and the school heads whose field is also in language from the DepEd. Private colleges or university professors were also asked to validate the instrument to make sure that the content was suitable not just in one context but generally acceptable. This was done during the international English teachers' conference in which the researcher is a member of the technical working 
group and steering committee. Moreover, the researcher also met during his free time individual practitioners, curriculum writers and validators.

Since the templates of the lesson plans follow the contents reflected in the DepEd Order, validation was not necessary. Hence, focus was just on how they were followed. These provided entries by the teachers which are part of the concerns of this study.

\subsection{Research Protocol}

The researcher considered ethical issues and protocols in conducting this study, considering information that needs to be treated with confidentiality according to the Philippines' data privacy law. In general, the protocol included information such as purpose and description of the study, confidentiality, right to refuse, and right to ask questions while in the process of conducting the study. Since the present study only utilized documents or the lesson plans crafted by the teachers, permission was still asked from them in case content needs to be revealed and published, considering the processes and purpose of the study.

\subsection{Statistical Treatment of Data}

Mean, frequency counts, ranking and percentages were the main statistical tools used in finding out answers to the problems enumerated in the statement of the problem section. Problem numbers 1 and 2, on the activities utilized and CLT strategies identified, frequency counts and content analysis were used. Problem number 3, on the alignment used mean, frequency counts, ranking and percentages, while answers to Problem 4, on implications for language teaching in the Philippines, were based on the content analyzed as results of the study.

\section{Results and Discussion}

\subsection{Strategies that the Teacher-Participants Used in their Daily Lesson Plans According to Type and Frequency}

All the strategies given by the teachers across lessons (1-26) in a semester and across 4As - the lesson phases were identified from the lesson plans. Grouping and or clustering of the strategies was based on Ramadan (2017) that are found to be also anchored on Richards (2006). This included task-completion activity, opinion-sharing activity, mechanical practice activity, information-transfer activity, reasoning-gap activity, information-gap activity, communicative activity, information-gathering activity, fluency activity, accuracy activity, meaningful practice activity, and others. Among the 17 (16 integrated and 1 standalone) Senior High Schools in the Schools Division Office of Antipolo City, following the sampling technique used as discussed in the earlier chapter, this study came up with 7 teacher-participants in which it turned out that they are those who were compliant to the required characteristics in this study. They were nominated and said to have the complete lesson plans across lessons 1-26 as required in the curriculum guide for those teaching Oral Communication in Context.

Results show that each teacher-participant used strategies that vary from one another as reflected on the percentages of the types of strategies. Noticeably, among the given categories of strategies, information-gap activity - with 25.620, 26.087, 36.567, $23.009,30.556,23.232$ and 32.000 from TP1 to TP7 respectively, got the highest percentage across participants and also across lessons and phases. The next was information-gathering activity - with 25.373/TP3, 16.814/TP4, and 16.000/TP7, while the second top most given strategies by the TP1 with 20.661 and TP5 with 20.883 were mechanical practice activity and taskcompletion activity from TP2 with 19.565 and TP6 with 12.121 percent. The rest of the categories of strategies were observed to have been utilized by the teacher-participants as reflected on their daily lesson plans. These got varied percentages.

However, there were types of strategies that the selected teacher-participants did not use. For instance, in TP1, TP3 and TP5 on communicative activity and in TP1, TP4 and TP5 on meaningful practice activity show that they have 0.000 percent, while opinion-sharing activity, and accuracy activity in TP5 were not observed, the same is true with fluency activity in TP5 and TP7 respectively. Albeit, it is good to note that there were other strategies given by the teacher-participants which the researcher could not classify according to the given categories. This might mean that they have been resourceful and skilful in thinking of other strategies.

These results of the process done in this study were congruent to the works of Shalem et al. (2018) on standardized lesson plans claiming that it became an accepted strategy to support and improve instructional practices in schools worldwide. This can also be attributed to Musselwhite and Wesolowski (2018) where lesson plans were evaluated according to domains such as instructional planning, instructional delivery, differentiated instruction, assessment uses and strategies. The same as the works of Koyunkaya and Tasdan (2019) which focused on the evaluation of lesson plan prepared by pre-service teachers at the end of a technology-based course. Using assessment rubric was found to be limited in reflecting instructional strategies or methodologies in teaching. The pre-service teachers had difficulty in fitting content, pedagogy and technology while preparing 
lesson plans based on the curriculum. Likewise, Canbazoglu Belici et al. (2016), where data was obtained from observations and lesson plans, mentioned the effective usage and integration of educational technology tools in their teaching.

Lesson plans prepared by the newbies in the profession are usually done with the technical assistance of seasoned teachers in the field, which is congruent to the work of Magana and Umek (2019). The present study shows that the lesson plans have been checked and provided with annotations or suggestions by their immediate heads and master teachers during its conduct. This would result in quality lesson plans that are validated and collaborated by the teachers. This was mentioned in Yuan and Zhang's (2016) work, which concluded that this would facilitate teachers' continuing developments.

Since the present study assessed the teacher-participants' daily lesson plans similar to the works cited herein, this simply means that there are rooms for enhancement on the part of the preparation of teachers' lesson plans especially in Oral Communication in Context. Teachers should really be cautious in choosing and utilizing appropriate strategies as the data revealed that there are CLT strategies found to be zero in the DLPs of the teachers. Like in Wen-Chi et al. (2017), activities should promote active engagement (Cheung Ruby and Chen, 2020) and highly interactive learning like those that promote oral proficiency.

\section{Content Analysis of the Types of Strategies Used in the Daily Lesson Plans of Oral Communication Teachers}

Details or actual samples of strategies across lessons and phases were given. The data reveal from top most given strategies as follows:

1. Task-Completion Activity which signifies the use of language to complete the tasks like puzzles, games and map reading. This got an overwhelming 24.880 percent from among the listed and utilized strategies. The actual samples listed in the grid can further be summarized into the following activities and related exercises that are given in the modules: games such as charade, family feud, mad gab and guessing game with scenario, differentiated group and individual activities with varied descriptions, individual and quiz with types, downloading and providing types and samples of speeches, filling in and completion of the grid, K-W-L, sentences and texts, lip-reading and pass message, reading activities with varied descriptions also, report presentations, scenes with given scenarios from the task cards with rubrics and the writing quote or relevant written activities. These strategies are said to be reflected on the lesson plans of the teacher-participants and are, most of the time, placed in task cards when they are in their respective classroom sessions already. This shows that the teacher participants are skillful in thinking and adopting strategies that let the students use the language through various task-completion activities. This practice is supported by Higgs (2020) in his study to support language arts instruction.

2. Opinion-Sharing Activity which consists of sharing values, opinions and beliefs. It may include listing and or ranking tasks. This was observed to have earned 18.660 percent as utilized and revealed on the table. From the actual samples listed, it can be regrouped by its thoughts into the match and tell including differentiating, commentary or feed backing with insights emphasizing affirmation and disagreements, utilization of grid for a purpose, in group listings with related discussion activity, share and talk or vice versa that emphasizes ideas, feelings, insights, realizations and experiences. This means that considering the given characteristics of this strategy, the teachers were able to utilized varied connected and related strategies as evident in the number of activities congruent to this from the individual lesson plans. However, making sure that these activities are within the interest and levels of the students as well as within the context of the subject, the work of Seltzer and de los Rios (2018), on stances and practices in translanguaging pedagogies with an understanding of raciolinguistic ideologies which ended on a call for designing a harmonized classroom learning, might be considered on this point since it talks about values, opinions and beliefs.

3. Mechanical Practice Activity with 11.962 percent is said to be the controlled practice activities. This includes repetition and or substitution drills. The strategies employed by the teacher-participants, included pronunciation and articulation drills with various descriptions, identifications like intonation patterns as a quiz, listening to audio materials, clips or text, oral drills with different descriptions, review in terms of terms and words then the rest were pen and paper activities. This result implies that the activities are in agreement with what is expected of the teacher-participants, although it can be seen that teachers have produced and adopted many strategies in carrying out the characteristics of this category. The results are also in agreement with Toro et al. (2019) that modeling, repetition and the like are some strategies that teachers are adopting to help learners develop communicative competence.

4. Information-Transfer Activity was next with 11.005 percent of utilization. This activity let the students take information from one form to another. It is said to be translating text or any idea to another genre like in graph or map. From the samples listed, it can be regrouped and said to have concept map or web mapping together with illustrations like models, diagram and charts or graphic organizer, and Venn diagram, which are the most commonly used strategies. It is also noted to have clippings for portfolio purposes, giving statement and perform principles discussed, outlining, picture talk or analysis with other descriptions a video clip or movie scene presentations. The data simply means that

Page | 95 
the lesson plans accomplished the expected strategies under this category. The teacher-participants were able to satisfy what is expected of them to utilize, considering this type of strategy. However, Baena (2013) asserted that employing real-life situations in the classroom requires authentic communication because it facilitates successful language learning. Baena claimed that teachers practiced a weak form of CLT which emphasizes structure and grammar skills. Information-transfer activity negates the use of structure and grammar in the sense that it just translates what could be taken from a text, a graph and related materials.

5. Reasoning-Gap Activity, which got 4.785 percent, infers from given information. In this type of activity, the teacherparticipants could utilize analogy, explaining, noting reflection from audio material listened to, open reflection and realizations that may also in sheets, scenario analysis, and think deeper. These strategies were culled from the teacherparticipants' individual lesson plans, which contain other descriptions reflected as directions in carrying out the said strategies. Similar to this case, Rahman et al. (2018), on belief and observed classroom practices, found that by articulating and reflecting, the teachers become aware of the meaning and impact of this belief on classroom practices. In this case, the teachers give such information to the students, and the students infer and, of course, reflect in order to meet the expected outcomes in this category.

6. Information-Gap Activity, with 3.828 percent, is characterized by getting information the learners do not have. This includes pairs to practice role-playing; dyad and sharing insights. From this result, the teacher-participants utilized skit or role play with various descriptions, brainstorming and discussion or lecture discussion in groups as task, paired work or dyad with situations, situation analysis, small group dynamics and Q \& A. Noticeably, it can be inferred that these strategies are hitting what is expected to be the outcomes of this category where students get information that they do not have through these strategies. Congruent to this, Rojas and Villafuerte (2018) claimed the influence of role-play as a technique in English class to boost learners speaking skills. According to them, it exposes learners to experience genuine situations that let them strengthen their abilities for communicating naturally and meaningfully.

7. Communicative Activity, with 4.306 percent, depicts real-life communicative situations like how to get to places. The results reveal that among the strategies under this category, the teacher-participants could create a story in groups, create-collaborate-communicate or C3, cross-country scenario, design a program for speech symposium, English conversation contest, following directions, impromptu speech and providing real life situations. These strategies made surely create an impact, as expected, on this type of strategies. This is similar to Pascual (2019) teaching proposal to be ideally implemented to develop communicative and digital competencies based on the digital genre like the travel blog. Likewise, Alamri (2018) believed that CLT stimulates learners' interest in learning by infusing the learning environment with new types of activities and materials that are both interactive and authentic.

8. Information-Gathering Activity, with 3.828 percent, uses language to collect information, and this is done through survey, interview, and searches. Teacher-participants who adopted strategies along this category used interview, observations, panel discussions in groups, psycho-test using statements posted on the board, self-audit or check using an assessment form, providing samples for analysis and of course the $Q \& A$. This implies that the teachers did not forget to develop the students' minds the skills expected to be observed from them through this information-gathering activity. However, Manzano's (2015) said that instructional materials, assessment tools, learners' roles, teachers' roles and institutional and or departmental policy were significantly found to be problems encountered by teachers in using CLT.

9. Fluency Activity, with 2.871 percent, is characterized by the natural use of language, achieving the use of meaningful communication. The teacher-participants have adopted strategies under this category such as speech delivery or presentation, listening to spoken poetry for a purpose, talk time or short speech and tongue twister reading. When adopted, these strategies help develop fluency of the language used on the part of the students. This can also be attributed to Kapurani (2016) claims that CLT is one of the best available foreign language teaching methods because it effectively improves students' language acquisition and use. This is when a contemporary interactive student-centered method is employed.

10. Accuracy Activity, with 2.871 percent, entails classroom use of language, formation of correct examples out of context, but do not require meaningful communication control choice of language. This includes results from dialogues with varied descriptions and add-ons, oral recitation and performance activity with rubrics. This means that when students are asked to make dialogues, read or analyze them following a rubric, they should have in mind the accuracy of their language and the samples they are presenting. This is also in relation to Guzman-Alcon (2019) who suggested the need 
to use strategies to draw attention to language and content and the importance of using a more even range of correction strategies.

11. Meaningful Practice Activity, with 2.392 percent, involves making meaningful choices and choosing correctly from lists. Here, the teacher-participants adopted strategies such as editing and rehearsing, evaluating speech with rubrics, highlighting tips on speech preparation and delivery and questions that may let the students identify. These strategies are said to be congruent to what is expected of this category. Along with this, Astuti and Lammers (2017) on cooperative learning focused on individual accountability, that individual students' performances and peer interaction can accommodate the teaching of four language skills and components. They argued that these activities promote learners' use of meaning in English and recommend that cooperative learning techniques should be followed to attain improved communicative competence which is the goal of CLT.

12. Others got 3.349 which cannot be classified under the given categories because the directions of the activity were not reflected. Only those that have clear directions on the basis of the objective of the day's session can be classified under any or among the categories listed and mentioned above. Noticeably, this was not the last in rank based on the computed percentage. It implies that there are teachers who just give activities or utilize strategies without thinking and considering the congruency of lesson objectives or learning competencies. This result confirms Maestre \& Gindidis (2016) findings that some teachers do not use CLT in the teaching of the English language. This also relates to Nguyen \& Gu (2020) on narrowing teaching content and shifting away from CLT.

\subsection{Teacher-Participants' DLP Strategies Assessed According to CLT Principles and Features in Each of the Following Phases: Activity, Analysis, Abstraction, and Application}

The result shows actual teacher-participants' daily strategies in their lesson plans classified according to the 4As and how they matched with CLT principles and features. Details on how these activities match the CLT standards were important to the researcher to determine specific recommendations for the teachers to meet CLT standards. These were labeled per lesson's phase, followed by their brief descriptions which are discussed further.

The codes used in this study where:

$1 \quad$ Match

P1 Authentic texts are used.

P2 There is focus on learning process.

P3 There is focus on learner's personal experiences.

P4 Language learning in the classroom is linked with language activation outside the classroom.

P5 Tasks that encourage negotiation of meaning are emphasized.

P6 In teaching grammar, encouragement of risk-taking and tolerance of errors are practiced.

F1 In communicative language teaching, meaning is paramount.

F2 Dialogues, if used, center around communicative functions and not normally memorized.

F3 Contextualization is a basic premise. Language learning is learning to communicate.

F4 Effective communication is sought.

F5 Drilling may occur, but peripherally.

F6 Comprehensible pronunciation is sought.

F7 Any device that helps the learners is acceptable - varying according to their age and interest.

F8 Attempts to communicate may be encouraged from the very beginning.

F9 Judicious use of native language is accepted where feasible.

F10 Translation may be used where students need or benefit from it.

F11 Reading or writing can start from the first day, if desired.

F12 The target linguistic system will be learned best through the process of struggling.

F13 Communicative competence is the goal (i.e., the ability to use the linguistic system effectively and appropriately).

F14 Linguistic variation is a central concept in materials and methodology.

F15 Sequencing is determined by any consideration of content, function or meaning that maintains interest.

F16 Language is created by the individual often through trial and error.

F17 Fluency and acceptable language is the primary goal. Accuracy is judged not in abstract but in context.

F18 Intrinsic motivation will spring from an interest in what is being communicated by the language.

F19 Students are expected to interact with other people, either in flesh, pair and group work, or writing.

F20 The teacher cannot know exactly what language the students will use. 
As revealed by the results, the actual DLP strategies used by the Oral Communication in Context teachers that matched CLT principles and features, the total matched strategies and their percentages are reflected on the last part of each phase from the 4As. The process of cross checking their matches, repeated strategies were counted as one only.

This resulted in a number of strategies that matched in each phase such as in Activity Phase, a total of 87 enlisted strategies but the highest percentage of the match was Principle 3 or P3 "There is focus on learner's personal experiences." with 95.40 percent, followed by P2 "There is focus on learning process." with 58.62 percent. But the least match was on P6 "In teaching grammar, encouragement of risk-taking and tolerance of errors is practiced." The top most Features are F19 "Students are expected to interact with other people, either in the flesh, through pair and group work, or in their writing." with 71.26, F7 "Any device that helps the learners is acceptable - varying according to their age and interest." with 42.53, F10 "Translation may be used where students need or benefit from it." with 39.08 and F20 "The teacher cannot know exactly what language the students will use." with 37.93 percent respectively, while the least features were F14 "Linguistic variation is a central concept in materials and methodology.', F18 "Intrinsic motivation will spring from an interest in what is being communicated by the language." and F6 "Comprehensible pronunciation is sought."

In the Analysis Phase, a total of 50 strategies was listed but the highest percentage of the match was P3 "There is focus on learner's personal experiences." with 98.00 precent, followed by P2 "There is focus on learning process." with 50.00 percent, while noticeably, P6 "In teaching grammar, encouragement of risk-taking and tolerance of errors are practiced." has no match. In the Features, F19 "Students are expected to interact with other people, either in the flesh, through pair and group work, or in their writing." got the top most match with 72.00 percent, followed by F7 "Any device that helps the learners is acceptable - varying according to their age and interest." with 44.00 percent. Note that F14 "Linguistic variation is a central concept in materials and methodology." got no match from the results.

The Abstraction Phase has a total of 49 listed strategies but the highest percentage of the match was P3 "There is focus on learner's personal experiences." with 91.84 percent, followed by P2 "There is focus on learning process." with 63.27 percent, while P1 "Authentic texts are used." and P6 "In teaching grammar, encouragement of risk-taking and tolerance of errors are practiced." with 6.12 percent placed in the least match. On the other hand, F19 "Students are expected to interact with other people, either in the flesh, through pair and group work, or in their writing." was on top of the match in terms of features with 77.55 percent, while F6 "Comprehensible pronunciation is sought." and F18 "Intrinsic motivation will spring from an interest in what is being communicated by the language." were on the bottom with 2.04 percent.

In the Application Phase, a total of 72 strategies was listed, but the highest percentage of the match was P3 "There is focus on learner's personal experiences." with 94.44 percent, followed by P2 "There is focus on learning process." with 65.28 percent. P6 "In teaching grammar, encouragement of risk-taking and tolerance of errors are practiced." with 9.72 percent was the least matched. For the features, F19 "Students are expected to interact with other people, either in flesh, through pair and group work, or in their writing." was on top of the match with 59.72 percent. This was followed by F7 "Any device that helps the learners is acceptable - varying according to their age and interest." and F10 "Translation may be used where students need or benefit from it." with 31.94 and 30.56 percent respectively. F18 "Intrinsic motivation will spring from an interest in what is being communicated by the language." with 1.39 percent was the least matched.

The parts of the daily lesson plan, as per DepEd Order No. 42, s. 2016, under Part IV or the Procedure include A-J as its sub-parts which are also classified and marked as to which letter is under the $4 A s$, to wit: parts $A B C$ are under the first A or Activity Phase, parts DE are under Analysis Phase, FG are under Abstraction, and HIJ are under Application Phase. In these phases, various and differentiated strategies can be done or given to the students for as long as they are aligned to the standards and other policy guidelines observed by the teachers in their respective classrooms. One strategy can be given to the students in any of the four phases, and in any of the lessons from the start to the last day of the semester for as long as it considers the teaching learning process that has an observable performance. This pertains and relates to the work of Gali et al. (2019), stating that communicative language teaching can be carried out as a set of principles related to language learning goals, how to learn a language with a learner, the types of classroom activities that best facilitate learning, and the role of the learner and teacher.

Among the 4As, the Activity Phase should be anchored to the following notes: accesses students' prior knowledge or activate schemas; leads to the development of objectives; is appropriate to the students' ability; should have clear and better instructions or directions; theme should be appropriate to the level of the students; can also be other activities or support activities to carry out objectives; should not be confined to one activity only; could be individual or group; includes strategies that suit where others are also being considered. Towards the end of these activities are things done that may also include questions leading to the next phase: analysis. The results prove that teachers were on the right track employing CLT-based activities in their 
classrooms that touch principles and features. Table 6 reveals that P3 "There is focus on learner's personal experiences." and F19 "Students are expected to interact with other people, either in the flesh, through pair and group work, or in their writing." with 95.4 and 71.26 percent, respectively are in agreement with what is expected in this particular phase. Data also further imply that the variations of the percentages on the matches show the extent of the strategies adopted by the teachers in their respective classrooms as El Karfa (2019) suggests that communicatively oriented attitudes and practices should be enhanced in many ways. This implies that the teachers were very resourceful and creative in the subject and in all other topics in the curriculum guide that they are teaching, even though they had varied and diverse learners. This finding concurs with Gali (2019), who mentioned that CLT can be carried out as a set of principles related to language learning goals, how to learn a language with a learner, the types of classroom activities that best facilitate learning, and the role of learner and teacher.

As to the preparation of strategies in this lesson's phase for students, learning styles and attitudes should also be considered, according to Natividad and Batang (2018). Similarly, when one employs strategies in the classrooms, methods that would really develop or enhance skills leading to communitive competence, Bagheri et al. (2019), and Cho \& Kim (2018) claimed that language play could be a good tool for teachers to foster students' communicative competence and to encourage them to be creative and explorative.

Since teachers are guided with the learning competencies reflected in the curriculum guide and have exhaustive resources for materials and references they can use for crafting and employing strategies in their respective classrooms, they must always think of alignment. Al-Mashaqba (2017) found that the English textbook used by the teachers has fulfilled 84 percent of communicative competence's criteria of good EFL textbook adopted from some experts including Nguyen et al. (2016) discussion on issues about classroom code-switching.

Yes, it is true that the strategies matched with some CLT principles and features. Still the notes for Analysis Phase should be the major considerations of the teachers who prepare lesson plans and execute the same in their respective classrooms. The Analysis phase is the processing part of the activities given in the first phase which observes the sequence of questions, how these questions are raised, and possible follow-up questions whenever necessary. This should also consider questions for students' deeper understanding, the teacher's note on how the students react to each question, or whether they answer the given questions or not, and lastly, if these questions lead to conclusion or transition to the next phase, which is Abstraction.

Similar to the findings in the first phase, this phase got P3 and F19 as the leading matches, with 98.00 and 72.00 percentages respectively. In the table, it can be noticed that there were least matches, like P6 and P1; then F18, F1, F15, F6, F12 and F5 \& F17. This may be associated with the works of Huang (2016) which claimed that teachers may face problems such as students' low L1 cognitive process and students' heterogeneous language skills in the same class. The same is true with Martinez Gomez (2019) on claims that teachers worked with traditional methods in transition communicative activities and focused on identifying the communicative activities that students are more receptive to. This result implies the need for teachers to consider the art of questioning, making sure that students' critical thinking skills will be developed at this lesson's phase.

The Abstraction Phase entails the discussion part where the teacher can add relevant information from various sources and learning materials. It is in this phase where the concept based on analysis is formed. It is also important that questions and the concept formed from the discussions should be written. Since this phase is where generalization of the lesson and discussions happen, this can be associated with Yang's (2016) claim that teachers' talk is an important way of mediating learners' cognitive processes.

It is true that there is congruency of the results from the activity, analysis and abstraction phases of the lesson as they revealed that P3 with 91.84 and F19 with 77.55 are the top-ranking principles and features' matches. The other percentages of matches simply reflect that there are specific strategies that could only be given or employed in this lessons' phase.

Finally, what a teacher should remember in the Application Phase are the following: this consolidates what has been learned and make it relevant using several methods like learning log, exit slips, sharing of products, debriefing on the process, performances, publications, real world activities, scenario, simulation, demonstration, case study and the like. In this phase, the teacher should also make sure to relate the concept to real life and/ or experiences.

From the result, it shows that P3 with 94.44 and F19 with 59.72 percent are on top of the match from principles and features. Since it is in this phase where assessments can be employed, Tran and Duong (2018) said that patterns of improvement may be observed in this phase. Likewise, AL-Garni and Almuhammadi (2019) claimed that in this phase, positive implications for continuous implementation of CLT teaching practices may be associated, in the sense that if the teacher sees that there is a need for some interventions leading to improvement, it can still be made. Added to that, Muhammad (2016) suggested policy makers 
consider CLT adoption in teaching English. Moreover, insights of West (2016) on benefits to students of CLT that are reflected on English textbook, Varghese and Karki (2018) on CLT as the most preferred teaching method in English, and Eliot (2016) on conclusion with reflection on current practices and implications, may be taken into consideration after this last lesson phase.

\subsection{Extents of Alignment of the Teacher-Participants' Identified CLT Strategies to the Prescribed DepEd Curriculum Guide in Terms of the Following: Content Standards, Performance Standards, and Assessment Types}

The result reveals the teacher-participants' CLT lesson strategies by occurrence and alignment to the DepEd curriculum guide in terms of content standards, performance standards and assessment types. The data present the 7 teacher-participants' total strategies adopted in their respective classrooms where it occurs in the 4 phases with a total of 176 for activity, 116 for analysis, 109 for abstraction and 134 for application. These were tallied in detail so as to arrive at the means of alignment to standards and assessment types.

Of all the listed activities in the four phases such as Activity - Analysis - Abstraction - Application, the Activity phase garnered 3.142 in the Content standard, and 2.920 in the Performance standard. In the Analysis phase, the results show 3.353, which noticeably was vertically aligned to the Content standard and 3.129 which fell under verbal interpretation of aligned to the Performance standard. In the Abstraction phase, the strategies gained 3.138 for Content and 2.945 for Performance standards respectively. Lastly, they reached 3.142 and 3.067 in the Content and Performance standards in the Application phase, interpreted as aligned.

In the same results, the activities were shown to be also aligned to the Assessment types with 3.037 ratings. It can be gleaned from the table that the only phase where there were ratings for Assessment types was the Application phase, because the evaluation part of all lessons in English that are performance-based and are adopted in the 4As, is included in the Application phase already.

These results imply that really the teachers teaching the subject are really good planners and executers of the plans made for the subject. They are also scrutinizing the learning competencies indicated in the curriculum guide and the standards reflected so that a seamless and flawless lesson that consider vertical and horizontal alignment is created. If consistently done by the teachers in their respective classrooms, the mastery of the skills and competencies expected of the students taking the course would surely be attained.

The result is an affirmation of Gulzar and Nasir (2019) on claims that alignment between standards and assessments is the key factor in a standard-based education system, and Combrinck et al. (2016) on the alignment of assessments and curriculum standards. Likewise, Ibrahim and Ibrahim (2017) examined matches of teaching English to communicative English language teaching and found that teachers were mostly unaware of CELT principles and know-how implementation. Swanson \& Hildebrandt (2017) on planning for instruction and alignment with CLT approaches. On the other hand, as this study aimed to propose a curriculum innovation in context, it considered Gamson et al. (2019) which from their survey raised the questions and cautions for today's reformers when rethinking curricula.

The alignment process was done in this study with the help of the invited inter-raters, each strategy listed and lifted from the individual lesson plans of the teacher-participants was subjected to scrutiny and agreement as to its alignment to the content standards, performance standards and assessment types utilizing the four-point scale which 1=Not Aligned, $2=$ Slightly Aligned,

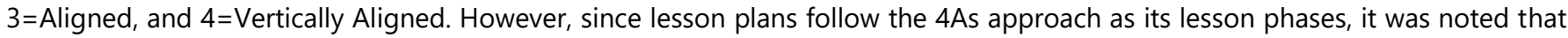
the alignment could not be observed from the 1st to $3 \mathrm{rd} \mathrm{A}$ in the 4As. This is because the assessment and evaluation given to the students are usually reflected on the last A which is the Application phase. Hence, only the Application phase had entries when it comes to alignment. This relates to Mahmadun Nuby et al. (2019) on aligning of curriculum and test format, and Ong et al. (2019) who mentioned reconstructing syllabuses to provide communicative class. In the same manner, the works of Tassone et al. (2018); Jai-Li et al. (2020) suggests designing curricula, pedagogies and assessments, as well as Tran et al. (2016); Dmith \& Mader (2017) that highlights curriculum and content standards on education reforms are found to be relatable to the present study.

\subsection{Implications of the Findings of the Study for Language Teaching in the Philippines}

Based on the results of this study, the following are the identified implications to Language Teaching:

1. The CLT is integrated in the curricula of the $\mathrm{K}$ to 12 programs in Philippines specifically in the SHS Oral Communication in Context course. Hence, there is a need to intensify the congruency of the classroom activities to the CLT principles and features. 
2. Lesson plans are crafted based on DepEd Order No. 42, s. 2016, because four phases on the procedure part could be observed. To enrich lessons more, an increased number of activities that are aligned to the standards could be employed dependent on the teachers' creativity and resourcefulness.

3. A training program on CLT and Curriculum Innovation aligned to this study could be implemented.

4. Continuous review of activities reflected on the lesson plans against the standards on the curriculum guide for the enrichment of the class as a whole should be observed by the teachers and their school heads and supervisors. This is associated with Moodie and Nam (2016) review of the recent studies on ELT using themes from the national curriculum as an organizing principle.

The works that served as support to the presented implications are those of Ittner et al. (2019 who mentioned curriculum reforms; Graves and Garton (2017) who explored influential ELT curriculum approaches to the teaching of English; Abahussain (2016) who mentioned an incompatibility between government's effort to develop TEFL and the practices used by English language teachers in their classes; and Dasi \& Pedersen (2016) who stated that language serves different purposes and entails different communicative requirements depending on the context in which it is used.

\section{Conclusion}

This study attempted to find out the types and frequencies of the activities given by the teachers to their students as reflected in their daily lesson plans. This also investigated which of the identified activities in the four phases of the lessons are considered CLT strategies considering the CLT principles and features. After such investigation, this study further determined the extent of alignment of these CLT strategies to the curriculum standards set by the DepEd for senior high school subjects.

The strategies used by the teacher-participants across lessons (1-26) in a semester and across 4As - the lesson phases were found to vary from one another as reflected on the frequency and percentages of the types of strategies. As used in their classrooms and reflected in their daily lesson plans, these varied strategies are classified similar to the types of CLT strategies by Ramadan (2017) that are found to be also anchored on Richards (2006). This includes: 1) task-completion activity, 2) opinionsharing activity, 3) mechanical practice activity, 4) information-transfer activity, 5) reasoning-gap activity, 6) information-gap activity, 7) communicative activity, 8) information-gathering activity, 9) fluency activity, 10) accuracy activity, 11) meaningful practice activity, and 12) others. There were other strategies employed by the teacher-participants which cannot be classified according to the given categories, it means that the teachers have been resourceful and skillful in thinking of other strategies.

On the basis of the classified types of strategies, it was found that:

- teacher participants were becoming skillful in thinking and adopting strategies that let the students use the language,

- teachers were able to utilize varied connected and related strategies as evident in the number of congruent activities reflected from the individual lesson plans,

- strategies were in agreement with what was expected of the teacher-participants, although it could be seen that teachers produced and adopted many strategies in carrying out the characteristics of a category,

- strategies adopted surely created an impact,

- teachers did not forget to develop in the minds of the students the skills that are expected to be observed from them,

- when adopted, these strategies really developed fluency of the language used on the part of the students,

- when students were asked to make dialogues, read or analyze them following a rubric, they were reminded to have in mind the accuracy of the language they are using and the samples they are presenting, and

- there were really teachers who just gave activities or utilize strategies without thinking and considering the congruency of their objectives or learning competencies.

A number of strategies were used in each of the four phases of the lesson, such as Activity-Analysis-Abstraction-Application (4As) that matched the CLT principles and features but varied on their respective percentages. These strategies were found to meet the expected characteristics of each phase as well as under their matched descriptions among the 6 principles and 20 features of CLT. It was also found that teachers really scrutinized the strategies they employed in their respective classes in all lesson's phases.

All the listed strategies in the four phases such as Activity - Analysis - Abstraction - Application, were found to be aligned to the Content standards and Performance standards. Noticeably, in the Analysis phase, the strategies were vertically aligned to the Content standard only. The same results revealed that the strategies in the Application phase were also aligned to the Assessment types reflected on the curriculum guide. The only phase where there were ratings for Assessment types was the Application phase because the evaluation part of all lessons in English that are performance-based and are adopted in the 4As, is included in and the Application phase already. 
Further, the teachers teaching the subject were really good planners and executers of the plans made for the subject. They also scrutinized the learning competencies indicated in the curriculum guide and the standards reflected so that a seamless and flawless lesson that considers vertical and horizontal alignment was created. If consistently done by the teachers in their respective classrooms, the mastery of the skills and competencies expected of the students taking the course would surely be attained.

The findings of the study brought implications to language teaching in the Philippines such as the following, but not limited to: - Intensification of congruency of classroom activities to the CLT principles and features;

- Standardization of lesson plans with enriched lessons containing strategies that are aligned to the standards reflected on the DepEd Order No. 42, s. 2016, and the curriculum guides;

- Innovation in the curriculum through training programs containing CLT strategies to promote communicative competence in the senior high school classrooms; and

- Continuous review of strategies and alignment reflected in the teachers' lesson plans against the standards on the curriculum guide with the help of master teachers, school heads, and supervisors.

Hence, the following conclusions were drawn:

1. The teacher-participants' strategies in their daily lesson plans vary according to types and frequencies in all four phases.

2. The teacher-participants' DLP strategies assessed in each of the following phases: Activity, Analysis, Abstraction, and Application match the CLT principles and features but vary on their respective percentages.

3. The teacher-participants' identified CLT Strategies are generally aligned to the prescribed DepEd curriculum guide in terms of the following: content standards, performance standards, and assessment types. Nonetheless, teachers need to still enhance their teaching skills specifically on the alignment of strategies so as to make sure that all learning competencies and teaching strategies will be vertically aligned and congruency of classroom activities with the standards will be observed.

4. Implications based on the findings of the study are avenues in the improvement of SHS classroom performances.

In the light of the conclusions drawn from this study, the following recommendations are hereby enumerated:

1. Teachers teaching Oral Communication in Context in the Senior High School classrooms should utilize varied CLT strategies in their classes and be clearly reflected on their Daily Lesson Plans based on the DepEd mandates and standards. They should exhaust all efforts and ask for technical assistance from language experts if needed.

2. Teachers should ensure that CLT strategies used are appropriate to the expected characteristics of the lesson's phases such as in the 4 As.

3. Teachers should be watchful in the preparation of the lesson plans, considering the alignment of strategies to the content and performance standards as well as assessment types that are reflected on the curriculum guide in Oral Communication in Context. 4. Teachers, master teachers, school heads and supervisors should address or consider the implications of the findings of this study on their strategic action planning.

5. Relevant study may be conducted considering exploration of other variables not covered in this study.

Funding: This research received no external funding.

Acknowledgements: The researcher expresses his sincere appreciation and deep gratitude to the persons who had contributed much that ultimately resulted in the completion of this study.

Conflicts of Interest: The author declares no conflict of interest.

\section{References}

[1] Abahussain, M. O. (2016). Implementing communicative language teaching method in Saudi Arabia: Challenges faced by formative year teachers in state schools. University of Stirling, United Kingdom: ProQuest Dissertations Publishing.

[2] Ahmed, M. K. (2016). Communicative Language Teaching: A practical scenario in the context of Bangladesh. Advances in Language and Literary Studies, 7(5), 97-104.

[3] Aicart, M. (2015). Language learning: The communicative approach. http://blog.languagejourneys.com/en/communicative-languageteaching/

[4] Alamri, W. A. (2018). Communicative Language Teaching: Possible alternative approaches to CLT and teaching contexts. English Language Teaching, 11(10), 132-138.

[5] AL-Garni, S. A., \& Almuhammadi, A. H. (2019). The effect of using communicative language teaching activities on EFL students' speaking skills at the University of Jeddah. English Language Teaching, 12(6), 72-86.

[6] Al-Mashaqba, N. J. H. (2017). Micro and macro content analysis of English textbook entitled "Mosaic One Listening and Speaking (Student's Book)" in the light of communicative competence. Advances in Language and Literary Studies, 8(2), 41-47. 
[7] Astuti, P., \& Lammers, J. C. (2017). Making EFL instruction more CLT-oriented through individual accountability in cooperative learning. TEFLIN Journal: A publication on the teaching and learning of English, 28(2), 236-259.

[8] Baena, T.A. (2013). The implementation of communicative language teaching (CLT) approach in English $1 / 101$ towards a faculty development program. ELTWeekly Insights for the Teachers of English. May 1, 2013. http://eltweekly.com/2013/05/the-implementation-ofcommunicative-language-teaching-clt-approach-in-english-1101-towards-a-faculty-development-program-by-tichie-ann-econg-baena/

[9] Bagheri, M., Hadian, B., \& Vaez-Dalili, M. (2019). Effects of the Vaughan method in comparison with the audiolingual method and the communicative language teaching on Iranian advanced EFL learners' speaking skill. International Journal of Instruction, 12(2), 81-98.

[10] Brown, H.D. (1994). Teaching by principles: An interactive approach to language pedagogy. New Jersey: Prentice Hall Regents.

[11] Canbazoglu Bilici, S., Guzey, S. S., \& Yamak, H. (2016). Assessing pre-service science teachers' technological pedagogical content knowledge (TPACK) through observations and lesson plans. Research in Science \& Technological Education; Abingdon, 34(2) (Jul 2016$)$ : $237-251$. DOI:10.1080/02635143.2016.1144050

[12] Cheung Ruby, Y. C., \& Chen, Y. (2020). Implementing the flipped classroom approach in primary English classrooms in China. Education and Information Technologies, 25(2) (Mar 2020): 1217-1235. DOI:10.1007/s10639-019-10012-6

[13] Cho, H., \& Kim, H. K. (2018). Promoting creativity through language play in EFL classrooms. TESOL Journal, 9(4) Dec 2018.

[14] Combrinck, C., Scherman, V., \& Maree, D. (2016). The use of Rasch competency bands for reporting criterion-referenced feedback and curriculum-standards attainment. Perspectives in Education, 34(4) (Dec 2016): 62-78. DOI:10.18820/2519593X/pie.v34i4.5

[15] Das, M. (2014). Necessity of communicative language teaching in India. Galaxy: International Multidisciplinary Research Journal, $3(4), 109$. www.galaxyimrj.com

[16] Dasi, A. \& Pedersen, T. (2016). How does the context of language use affect the perception of language barriers?, in Tina C. Ambos , Björn Ambos, Julian Birkinshaw (ed.) Perspectives on Headquarters-subsidiary Relationships in the Contemporary MNC (Research in Global Strategic Management, 17) Emerald Group Publishing Limited, pp.369 - 400.

[17] Elliott, L. (2016). Experiential learning informs classroom instruction: Teaching environmental conservation in a middle school Spanish classroom. Excellence in Education Journal, 5(1), 24-52.

[18] El Karfa, A. (2019). Communicative orientation of English language teaching classrooms in Moroccan secondary schools. English Language Teaching, 12(11), 97-112.

[19] Fagan, K. P. (2019). The problems of communicative language teaching for Chinese student teachers in an American TESOL practicum and our post-lesson dialogue for solutions. ProQuest LLC, Ph.D. Dissertation, Vanderbilt University. ERIC Number: ED601765.

[20] Gali, G. V., Fakhrutdinova, A. V. \& Gali, A. I. (2019). Methods of foreign language teaching to linguistically gifted students. International Journal of Higher Education, 8(8), 1-4.

[21] Gulzar, K. \& Nasir, M. (2019). An analysis of alignment between secondary school Mathematics standards and the assessments 2013 and 2014 of the Board of Intermediate and Secondary Education Lahore Punjab, Pakistan. Bulletin of Education and Research, $41(2), 11$.

[22] Gamson, D. A., Eckert, S. A. \& Anderson, J. (2019). Standards, instructional objectives and curriculum design: A complex relationship. Phi Delta Kappan, 100(6), 8-12. DOI:10.1177/0031721719834022

[23] Guzmán-Alcón, I. (2019). Investigating the application of communicative language teaching principles in primary-education: A comparison of CLIL and FL classrooms. English Language Teaching, 12(2), 88-99.

[24] Hedge, T. (2000). Teaching and learning in the language classroom. New York: Oxford.

[25] Higgs, J. (2020). Digital discourse in classrooms: Language arts teachers' reported perceptions and implementation. Research in the Teaching of English, 55(1), 32-55.

[26] Huang, S-H. (2016). Communicative language teaching: Practical difficulties in the rural EFL classrooms in Taiwan. Journal of Education and Practice, 7(24), 186-202.

[27] Ibrahim, M. K. \& Ibrahim, Y. A. (2017). Communicative English language teaching in Egypt: Classroom practice and challenges. Issues in Educational Research, 27(2), 285-313.

[28] Ittner, D., Hagenauer, G. \& Hascher, T. (2019). Swiss principals' emotions, basic needs satisfaction and readiness for change during curriculum reform. Journal of Educational Change, 20(2), 165-192. DOI:10.1007/s10833-019-09339-1

[29] Jia-Li, H., Chen, H-C., Chun-Ping, W. \& Jen-Chin, H. (2020). Construction and application of teacher professional standards and curriculum baseline for preservice teacher education. Jiaoyu Kexue Yanjiu Qikan, 65(2), 1-35. DOI:10.6209/JORIES.202006_65(2).0001

[30] Kapurani, E. (2016). "Results of implementing communicative language teaching method in English language learning in 9-Year elementary schools. (Albanian Context)," European Journal of Language and Literature Studies Articles, European Center for Science Education and Research, 2, January-A.

[31] Koyunkaya, M. Y. \& Taşdan, B. T. (2019). Assesment of pre-service Mathematics teachers' lesson plans in terms of technology integration. Eskisehir Osmangazi Universitesi Sosyal Bilimler Dergisi, suppl. Özel Sayi, 20, 1137-1166. DOI:10.17494/ogusbd.555139

[32] Maestre, JL. T. \& Gindidis, M. (2016). Teachers' beliefs, practices and challenges in using communicative language teaching (CLT) in an ESL context in the Philippines. The Asian Conference on Language Learning 2016. Official Conference Proceedings. The International Academic Forum. www.iafor.org

[33] Magajna, Z. \& Umek, M. (2019). Prospective teachers' lesson plans. Revija za Elementarno Izobrazevanje, 12(3), 325-350. DOI:10.18690/rei.12.3.325-350.2019

[34] Mahmadun Nuby, M. H., Rashid, R. A. \& Rakibul Hasan, M. (2019). Practices and outcomes of communicative language teaching in higher secondary schools in rural Bangladesh. Qualitative Research in Education, 8(2), 148-181.

[35] Manzano, B. A. (2015). English teachers' beliefs, practices, and problems encountered in using communicative language teaching (CLT). International Journal of Education and Research, 3(3) www.ijern.com

[36] Martinez Gómez, A. J. (2019). Transitioning to communicative activities in a primary-level EFL classroom in the Dominican Republic. Online Submission, Master's Thesis, Universidad Internacional Iberoamericana. Publication Date: 2019-Feb-2.

[37] Moodie, I. \& Nam, H-J. (2016). English language teaching research in South Korea: A review of recent studies (2009-2014). Language Teaching, 49(1), 63-98. DOI:10.1017/S026144481500035X 
[38] Muhammad, Z. (2016). Pakistani government secondary schools students' attitudes towards communicative language teaching and grammar translation in Quetta, Balochistan. English Language Teaching, 9(3), 258-270.

[39] Musselwhite, D. J. \& Wesolowski, B. C. (2018). Evaluating the psychometric qualities of a rating scale to assess pre-service teachers' lesson plan development in the context of a secondary-level music performance classroom. Journal of Research in Music Education, 66(3), 338-358. DOI:10.1177/0022429418793645

[40] Natividad, M. R. A. \& Batang, B. L. (2018). Students' perceptual learning styles and attitudes toward communicative language teaching. TESOL International Journal, 13(4), 104-120.

[41] Navidinia, H., Mobarak, M. \& Malekzadeh, F. (2019). Investigating the effect of noticing on EFL students' speaking accuracy. International Journal of Instruction, 12(1), 83-98.

[42] Nguyen, H. \& Gu, Y. (2020). Impact of TOEIC listening and reading as a university exit test in Vietnam. Language Assessment Quarterly, 17(2), 147-167.

[43] Nguyen, N. T., Grainger, P. \& Carey, M. (2016). Code-switching in English language education: Voices from Vietnam. Theory and Practice in Language Studies, 6(7), 1333-1340. DOI:10.17507/tpls.0607.01

[44] Nunan, D. (1995). Communicative tasks and the language curriculum. TESOL Quarterly, 25(2), 279-295.

[45] Ong, C. G., Maramara, E. S. \& Flores, C. (2019). Communicative teaching in the tertiary level. International Association for Development of the Information Society, Paper presented at the International Association for Development of the Information Society (IADIS) International Conference on Educational Technologies (6th, Hong Kong, Feb 8-10, 2019).

[46] Patton, M. Q. (2001). Qualitative evaluation and research methods (3rd ed.). Newbury Park, CA: Sage Publications.

[47] Pascual, D. (2019). Learning English with travel blogs: A genre-based process-writing teaching proposal. PROFILE: Issues in Teachers' Professional Development, 21(1), 157-172.

[48] Rahman, M. M., Pandian, A. \& Kaur, M. (2018). Factors affecting teachers' implementation of communicative language teaching curriculum in secondary schools in Bangladesh. The Qualitative Report, 23(5), 1104-1126.

[49] Rahman, M. M., Singh, M. K. M. \& Pandian, A. (2018). Exploring ESL teacher beliefs and classroom practices of CLT: A case study. International Journal of Instruction, 11(1), 295-310.

[50] Ramadan, M. (2017). Seven Kinds of CLT Activities to Build up Students' Communicative Competence. English Language Teaching \& Testing Guide. https://elttguide.com/seven-kinds-of-clt-activities-to-build-up-students-communicative-competence/

[51] Richards, J. C. \& Rodgers, T. S. (2001). Approaches and methods in language teaching. 2nd ed. New York: Cambridge.

[52] Richards, J. C. (2006). Communicative language teaching today. United States of America: Cambridge University Press.

[53] Rojas, M. A. \& Villafuerte, J. (2018). The influence of implementing role-play as an educational technique on EFL speaking development. Theory and Practice in Language Studies, 8(7), 726-732. DOI:10.17507/tpls.0807.02

[54] Seltzer, K. \& de los Ríos, C. V. (2018). Translating theory to practice: Exploring teachers' raciolinguistic literacies in secondary English classrooms. English Education, 51(1), 49-79.

[55] Shalem, Y., De Clercq, F., Steinberg, C. \& Koornhof, H. (2018). Teacher autonomy in times of standardized lesson plans: The case of a primary school language and Mathematics intervention in South Africa. Journal of Educational Change, 19(2), 205-222. DOI:10.1007/s10833-0189318-3

[56] Smith, B. \& Mader, J. (2017). Align your curriculum with the ISTE standards. The Science Teacher, 84(5), 8.

[57] Silverman, D. (2006). Interpreting qualitative data: Methods for analyzing talk, text and interaction. (3rd ed.). Sage Publications Ltd.

[58] Swanson, P. \& Hildebrandt, S. A. (2017). Communicative learning outcomes and world language edTPA: Characteristics of high-scoring portfolios. Hispania, 100(3), 331-347.

[59] Tassone, V. C., Catherine O'M., McKenna, E., Eppink, H. J. \& Wals, A. E. J. (2018). (Re-)designing higher education curricula in times of systemic dysfunction: A responsible research and innovation perspective. Higher Education, 76(2), 337-352. DOI:10.1007/s10734-017-0211-4

[60] Toro, V., Camacho-Minuche, G., Pinza-Tapia, E. \& Paredes, F. (2019). The use of the communicative language teaching approach to improve students' oral skills. English Language Teaching, 12(1), 110-118.

[61] Tran, D., Reys, B. J., Teuscher, D., Dingman, S. \& Kasmer, L. (2016). Analysis of curriculum standards: An important research area. Journal for Research in Mathematics Education, 47(2), 118.

[62] Tran, T. Q. \& Duong, T. M. (2018). The effectiveness of the intercultural language communicative teaching model for EFL learners. AsianPacific Journal of Second and Foreign Language Education, 3(6).

[63] Varghese, V. \& Karki, P. (2018). An analysis of preferred methods of teaching and learning English language in Bangalore, India. Journal on English Language Teaching, 8(4), 36-48.

[64] Wen-Chi, V. W., Chen Hsieh, J. S. \& Yang, J. C. (2017). Creating an online learning community in a flipped classroom to enhance EFL learners oral proficiency. Journal of Educational Technology \& Society, 20(2), 142-157.

[65] West, A. J. (2016). Adaptation of communicative language teaching methodology to an English textbook for English language learning of NIDA students. PASAA: Journal of Language Teaching and Learning in Thailand, 52, 25-52.

[66] Yang, X. (2016). An analysis of discourses in CLT from sociocultural theory perspective. Theory and Practice in Language Studies, 6(1), 194198. DOI:10.17507/tpls.0601.25

[67] Yuan, R. \& Zhang, J. (2016). Promoting teacher collaboration through joint lesson planning: Challenges and coping strategies. The Asia Pacific Education Researcher, 25(5-6), 817-826. DOI:10.1007/s40299-016-0300-7

[68] _. Opportunity Network (July 2018). http://www.opportunityjobnetwork.com/job-resources/help/top-10-skills.html 